\title{
Translation of Biomedical Literature From a Perspective of Skopos Theory
}

\author{
ZHANG Lifang, SHEN Xun \\ University of Shanghai for Science and Technology, Shanghai, China
}

\begin{abstract}
The frontier studies about bio-medicine have a large blowout in recent years, so the translation of bio-medical literature is significant in terms of research. Under the guidance of Skopos theory, the authors analyze the use of different translation skills, such as, addition, omission, conversion, division, and combination, to solve the difficulties encountered in the process of translation. Such translations skills can help to overcome translation problems and achieve good communicative effect of scientific and technological texts.
\end{abstract}

Keywords: Skopos theory, biomedical literature, translation skill

\section{Introduction}

Biomedicine is a cutting-edge interdisciplinary subject developed by the theoretical methods of medicine, life sciences, and biology. It is a discipline that uses biological and engineering techniques to solve problems in life science and medicine. Biomedicine is closely related to the formation and development of biotechnology, which is an important engineering field related to improving the level of medical diagnosis and human health. With the advancement of science and technology in the 21st century and the development of human society, people are becoming less and less satisfied with material abundance and enjoyment. Medical health, life science, and other related fields have gradually attracted more and more researcher's attention. The frontier studies about biomedicine have a large blowout in recent years, so the translation of this type of literature is significant in terms of research.

\section{Literature Review}

In 1971, Reiss put forward the prototype of functionalist translation theory in the book Possibility and Limitation of Translation Criticism. Later, her student Vermeer succeeded in the development and taking a breakthrough of his thoughts.

In 1970, Vermeer introduced the term "Skopos" into translation theory as a terminology for describing translation purpose and translating behavior. He believes that translation is a kind of communicative behavior based on the source language text with certain purposes. Vermeer detaches translation theory from the shackle of original text theory. In 2006, Nord inherits Vermeer's Skopos theory and systematically summarizes various academic ideas of teleology.

ZHANG Lifang, master, associate professor, Teaching and Research Center of College English, University of Shanghai for Science and Technology, Shanghai, China.

SHEN Xun, bachelor, School of Medical Instrument and Food Engineering, University of Shanghai for Science and Technology, Shanghai, China. 
The central idea of Skopos theory is that translation is a behavior; the translator may choose one of the translation strategies that it is the best way to achieve its intended translation purpose. The translator needs to consider various factors in the translating process, for instance, the purpose of translation, the situation of the recipient's target culture, the cultural situation of the translator, the relationship between the target language culture, and the source language culture, etc.

The three basic principles of Skopos theory are: the principle of purpose, the principle of coherence, and the principle of faithfulness.

The principle of purpose believes that the most important factor in the translation process is the purpose. The "principle of purpose" is the first principle that all translation activities should follow. Translation can play a role in the way that the recipient of the target language expects the difference between the cultural background of the original language and the target language, so that the purpose of the translation determines the translation behavior, that is, the outcome determines a method.

The principle of coherence means that translation must conform to the intra-textual coherence criterion, which requires that the information generated by the translator must be interpretable in a way that is consistent with the target recipient's context. Therefore, the translator should fully consider the cultural background and social environment of the target recipient, and create a translation meaningful to the recipient. That is to say, the translation is acceptable and readable and is meaningful in the context of the target language and culture. Only this kind of information exchange can be successful.

The principle of faithfulness means that there should be inter-textual coherence between the original text and the translation version. That is to say, the translation version should be faithful to the original text; specifically, the contents of the original text, the cultural colors, and the style of the source language should be faithfully conveyed. The translator's faithfulness to the original text depends on the translator's understanding of the original text and the purpose of the translation.

Zhao Weijiang and Luo Hua (2005) analyze the translation difficulties of nouns, verbs, adjectives, adverbs, and prepositions in biomedical English, providing a reference for the translation of biomedical literature. Zhang Chenxiang (2008) has systematically expounded the theory of functional purpose, and on this basis discussed the use of functional teleology in applied translation. Zhu Hongbin and Li Xueming (2017) explore the translation and proofreading of the abstracts of medical papers from the perspective of Skopos theory.

So far the studies on translation of biochemical documents at home are concerned with either class of words or abstracts of thesis; few studies are about the characteristics of biochemical text and the logically determined translation skills.

\section{Translation of Biomedical Literature}

In section three we will explore the stylistic characteristics of biochemical literature and then address the translation skills which are correspondingly adopted.

\section{Stylistic Characteristics of Biomedical Literature}

The biomedical literature belongs to scientific and technological literature, which aims to disseminate the latest information in the field of life science, carry out scientific and technological exchange, and promote scientific development. Therefore, this kind of literature is different from literary works, which aim at focusing on emotional bursting, image shaping, and pursuing artistic appeal. The general characteristics of scientific 
literature are logically strict, objective and clear, and accurate in diction. The scientific literature often prefers long sentences, noun phrases, passive voices, less personal pronouns, descriptive adjectives to maintain objectivity and accuracy of the text, and avoid flamboyant exaggeration. To avoid flamboyant exaggeration, it is required to be precise, well-organized, fluent, and professional or technical in wording.

In the connection of wording, the vocabulary of biochemical documents is mainly divided into professional vocabularies and acronyms. Due to the high rigor and professionalism of science and technology articles, the use of words must be accurate and rigorous. The professional vocabularies in scientific English can be divided into semi-technical vocabularies and pure technical vocabularies. Semi-technical vocabularies mean that common vocabularies are applied to a particular field and have special meanings. Pure sci-tech vocabularies are relatively narrow in meaning, and only represent a specific scientific or technical definition in technical English. Their frequencies of occurrence are not high. In the biomedical literature, semi-technical vocabularies such as “imaging”, we commonly render them into “成像、镜像、映像”. In biomedical English, “imaging” should be translated into “扫描”. Another example is the “receptor”, which should be translated into “受体” (a component of cell wall proteins that responds to specific antibodies) in biomedical English. It may be translated into “接收器” used to receive signals in electronic communication English. Pure technical terms include rhabdomyosarcoma (横纹肌肉瘤), mitochondria (线粒体), lymphatics (淋巴组织).

Another feature of biochemical literature is the use of acronyms. The commonly used terminologies in biochemical literature have corresponding abbreviations, such as DNA (deoxyribonucleic acid, 脱氧核糖核 酸), ECG (electrocardiograph, 心电), PPT (pulse transit time, 波形传播时间), and suchlike.

In the connection of sentence, the striking feature of biochemical documents is the widespread use of passive voice. The passive voice is heavily used in scientific and technological English articles because technical English pays more attention to objectivity, and passive voice emphasizes objective facts better than active voice. The passive voice makes the text more precise and clearer than the active voice, in line with the style of scientific and technological articles.

In terms of temporal relation, general present tense is more frequently used in biochemical literature, including present perfect tense, general future tense, sometimes a simple past tense which is also employed, in particular, when an action is involved. The general present tense is used to eliminate any misunderstanding associated with time, making the text more rigorous. The general future tense is used to propose future research protocols or research ideas. A simple past tense is often used to describe discoveries and phenomena that cannot be confirmed as natural laws and eternal truths. The descriptions are only the results of the study at that time.

\section{Translation Skills of Biomedical Literature}

Five important translation skills will be illustrated in detail when we translate bio-chemical literature.

Addition. The translation skill of addition means that in the process of translation, if necessary, some words that are not in the original text can be added to. This skill is mainly used when the translation does not fully conform to the grammar and rhetorical habits of Chinese. The use of addition can make the translation version better close to the target context, making it easier for the reader to understand and meet the requirement of the principle of purpose. For instance:

(1) Some important issues within the field include cell isolation, control of cell organization and function, up scaling to full bioartificial tissues, and biomaterial fabrication. 
组织工程领域的重要课题包括细胞分离、细胞组成和功能的控制、人造生物组织的升级和完善、以 及生物材料的制造等。

The translation of this sentence uses the addition. If you translate "field" directly into “领域”, the translation of this sentence will not be able to take on the above. Translators have translated "field" into "(组织 工程)领域”, in consideration of the above context, making the translation easier to understand and satisfying the cultural background and needs of the target audience.

(2) Success rates rely on fluid flow rate through the column, as well as the density of packed beads and dimension ratios of the column.

反应器的成功率取决于液流速度, 细珠的密度和柱体维度的比例。

If “success rates” are directly translated into “成功率”, the reader may be confused whether the success rate is the success rate of the above steps or the success rate of the reactor. The translators combine the above with "liquid flow velocity, density of the beads and cylinder dimensions" to understand that the success rate here refers to the success rate of the reactor. Therefore, the translators use the skill of addition here to translate “success rates” into “(反应器的)成功率”. This makes the target audience better understand and accept, which completes the communication and guiding function of the translated text, and follows the principle of purpose.

(3) Some molecules, such as oxygen, carbon dioxide, and water, can easily cross the plasma membrane, whereas other substances, such as large molecules and ions, must move through the protein channels.

氧、二氧化碳和水等分子可以轻易穿过细胞膜, 而其他大分子和离子等就必须经过蛋白质通道运输。

The part of "move through the protein channels" in the original text should be translated directly into “通 过蛋白质通道”. However, if you translate it in this way, you may make the reader misunderstand the meaning of the original text. The phrase "move through" here relies on the active role of proteins in the process of macromolecule and ion transport, so it is more reasonable to translate it into “经过蛋白质通道(运输)”, avoiding misunderstandings of readers and achieving the communicative purpose of translation.

Omission. The skill of omission means that the translator omits some words in the original text according to the grammar and rhetorical habits of the target language in the process of translation. These omitted words are either unintentional or unnecessary. This method can make the translation more concise, rigorous, and refined. For instance:

(4) If you know the frequency, you can find the wave length.

如果知道频率, 就可以求出波长。

The translation of this sentence uses the skill of omission. English pronouns are complex and are frequently used. However, Chinese pronouns are comparatively less often used. Therefore, in the process of translation, the omission is often used to save the pronouns in English from being translated. So "if you know" can better be translated into “如果知道”; “you” is omitted in the two clauses. This method makes the translation avoid semantic ambiguity and overlapping of words, and is more used in the translation of a scientific and technological text.

(5) Although beneficence and nonmaleficence were regarded merely as concomitant to the craft of medicine in classical Greece and Rome, the emphasis upon compassion and the brotherhood of humankind, central to Christianity, increasingly made these norms the only acceptable motives for medical practice.

虽然这两条原则在古希腊和古罗马医疗技术中只是附属品, 然而, 基督教所强调的人类同情心和兄 弟情使这两条原则逐渐变成了唯一可接受的行医动机。 
Omission is employed in the translation of this sentence; the word "regarded" is omitted in the translated version. It is obvious that according to the language habits of Chinese, the word "regarded" (被认为) here can be omitted and translated into “这两条原则在古希腊和古罗马医疗技术中只是附属品”. It is more streamlined and conforms to the language style of a technical article.

(6) If the osmolarity inside and the osmolarity outside of the cell are out of balance, there will be a net movement of water from the side of the plasma membrane where it is more highly concentrated to the other until equilibrium is achieved.

如果细胞内外的渗透浓度不同, 那么水分子就会从浓度高的一侧流向浓度低的一侧, 直到平衡为止。

The translation of this sentence uses the omission. The "there be" structure in the original text indicates a state of existence, and at the time of translation, it is not necessary to translate “there be" into “将有” word by word; its meaning is contained in the verb of the clause.

Conversion. Because of the differences in grammar and the way to express between English and Chinese, under the guidance of Skopos theory, the translation should be in agreement with the context of the target language. In many cases, the translators need to make some changes, such as the adjustment of word order, the change of sentence structure, the conversion of sentence expression, and the change of word class. Conversion is particularly used to refer to the change of word class without changing its meaning in the process of translation. For example:

(7) They are beneficence, which is the provision of benefits, and nonmaleficence, which is the avoidance of doing harm.

行善就是提供帮助; 不伤害就是避免伤害。

The change of word class is used in translating this sentence. In the process of translation, the nouns “provision” and “avoidance” are translated into the verbs “提供” and “避免” in Chinese. Since the scientific texts prefer to use more nouns, the conversion of nouns into verbs is more in line with Chinese expression habits, which makes the translation more fluent, and achieves the communicative function of the translation.

(8) Prosthetics are defined as any "internal or external device(s) that replace lost parts or functions of the neuroskeletomotor system” and may be either orthopedic or externally controlled.

假肢的定义是 “任何用于替代神经骨骼运动系统的残缺部分或者残缺功能的体内或体外装置”，它 们要么是矫形器, 要么是体外控制器。

The original text of this sentence uses the passive voice "prosthetics are defined", which is often used in scientific and technological English. When translating this sentence, the translators change the passive voice of English into the active voice of Chinese, and change the word class of “define” from a verb “被定义” into a noun “定义”, which makes the translation more fluent, concise, and congruous to the Chinese context.

(9) In designing a "replacement" limb for the human body, an engineer is buried under an obscene amount of considerations and design constraints.

在设计人体肢体的 “替代品” 时, 工程师需要考虑许多因素和约束条件。

The change of voice and word class is also conducted in the translation of this sentence. Because of the characteristics of technical English, the passive voice is more used in the technical articles, for example, "an engineer is buried under...consideration" in Example (9). Under the guidance of the principle of purpose, the translators hope that the translation will be better accepted by the target audience. Therefore, the translators use the skill of conversion to translate the passive voice into the active one, and change a noun into a verb, “工程师 
需要考虑”, according to the usage habits of Chinese.

Division. The skill of division is to divide a long sentence into necessary segments and translate them into several shorter sentences. Long sentences are frequently used to show strict logic in scientific and technological English. Therefore, under the guidance of the principle of purpose, the use of division can avoid the lengthy and vague sentences of the target version. For example:

(10) Under resonant excitation, au nanocrystals have the unique ability to concentrate the free-space optical field within subwavelength regions adjacent to their surfaces.

在共振激发下, 金纳米晶体获得了独特的能力, 它能够将自由空间光场集中在与其表面相邻的亚波 长区域内。

In this sentence, if the long sentence is translated according to the original language order, it will be lengthy and circumvented, which is inconsistent with the usage habits of Chinese. Therefore, the translators use the skill of division to translate the long prepositional phrase “under resonant excitation" into a sentence “在共 振激发下”, and cut the rest into two Chinese clauses. It conforms to the expression habit of the target language, making the translation more readable and acceptable to Chinese readers.

(11) Whereas decades ago the primary objectives of the biomedical engineer consisted of device design, modern feats are more likely to involve biochemistry and gene therapy than screws, nuts, and bolts.

早在数十年之前, 生物医学工程工程师的主要目标是设计装置, 但是, 目前的新技术涉足更多的是 生物化学和基因治疗, 而不是螺钉、螺母和螺栓。

The skill of division is also used in the translation of Example (11). This sentence is a long complex sentence consisting of a subordinate clause introduced by "whereas" and a main clause. In order to make the translation version semantically clear and more congruous to the usage habits of Chinese readers, it is necessary to divide the long sentence into three short sentences in Chinese.

(12) With the development of modern respirators, however, the medical profession encountered an increasing number of situations in which a patient with irreversible brain damage could be maintained almost indefinitely.

然而, 随着先进呼吸机技术的发展, 遭受不可逆脑损伤的病人依靠呼吸机几乎可以一直维持下去, 这种病例越来越多。

In the process of translation, the prepositional phrase introduced by "with" is divided into a clause, and the attributive clause introduced by "in which" in the sentence is actually put at the end of the sentence. If you do not use the translation skill of division, the translation will be top-heavy; therefore this main part is divided into two Chinese clauses. After dividing the main part into two clauses, the translation is more in line with the Chinese context, which makes it more intelligible, and realizes the communicative function of science and technology English.

Combination. Combination is a translation skill which is opposite to the translation skill of division. It is applicable to some long and loose sentences. Combination can be used to make the translation compact, well organized and rigorous. For example:

(13) Generally speaking, the typical metal conducts electricity and heat. It shows lustrous surface, usually with white, or so-called metallic luster. It is ductile and malleable.

一般来说, 典型的金属能够导热导电, 表面有光泽, 具有延展性和可锻性。

The translation of this sentence uses the skill of combination. The original text has three simple sentences. If the translation is in the form of the original text, the translation will appear as a repetition of the subject and 
does not conform to the reading habits of Chinese. Therefore, the translators prefer to combine three simple sentences into one sentence. The subject "typical metal" of the first sentence is still the subject of Chinese, and the subjects of the other two sentences are omitted. This makes the translation more in line with the reading habits of the target readers, increasing the readability of the translation.

(14) Human bodies are divided into two main regions: axial and appendicular. The axial part consists of the head, neck, thorax (chest), abdomen, and pelvis, while the appendicular part consists of the upper and lower extremities.

人体分为主干和四肢两个部分，主干包括头、颈、胸、腹和骨盆，四肢包括上肢和下肢。

The translation of this sentence combines two sentences into one sentence, which makes the logical structure more obvious and the target version more compact.

(15) The cavities of the body hold the internal organs. The major cavities are the dorsal and ventral body cavities, while smaller ones include the nasal, oral, orbital (eye), tympanic (middle ear), and synovial (movable joint) cavities.

体腔用于容纳身体内部的各种器官, 主要有背侧体腔和腹部体腔, 还有一些较小的腔室, 包括鼻腔、 口腔、眼窝、中耳鼓室以及活动关节的关节腔等。

The translation of this sentence also uses a combination skill to translate two single sentences into one sentence. After the translation, "cavities" is still the subject of the sentence, and the subject of the other sentence is omitted. This makes the translation avoid repetition, and achieves smooth and concise effect of a scientific and technological text.

\section{Conclusion}

Biomedical literature has a large amount of terms, specialized knowledge, and language has complex sentence structure, so it is inevitable that many difficulties are encountered in the process of translation. Under the guidance of Skopos theory, the authors analyze the use of different translation skills in the translation process, such as, addition, omission, conversion, division, and combination, and provide sufficient illustrations which successfully employ these translation skills for reference. Based on these examples, the authors conclude that such translation skills can solve the difficulties encountered in translating biochemical documents well and can achieve good communicative effect of scientific and technological texts by bearing the idea of translation purpose in mind.

\section{References}

Bell, R. T. (2001). Translation and translating: Theory and practice. Beijing: Foreign Language Teaching and Research Press. Bian, J. H. (2008). Heritage and transcendence: A study of functionalist Skopos theory. Beijing: Chinese Social Science Press.

Chen, X. W. (2004). Functional purpose theory and applied translation. In M. Z. Fang and Z. M. Mao (Eds.), A coursebook of applied translation (pp. 113-117). Shanghai: Shanghai Foreign Language Education Press.

Liu, J. L. (2017). Translation and writing of biomedical papers. Changsha: Hunan University Press.

Mark, S., \& Cowie, M. (2004). Dictionary of translation studies. Shanghai: Shanghai Foreign Language Education Press.

Nord, C. (1991). Text analysis in translation: Theory, methodology and didactic application of a model for translation-oriented text analysis. Amsterdam: Rodopi.

Zhang, N. F. (2004). Translation criticism in China and west with a single purpose. Beijing: Tsinghua University Press.

Zhao, W. J., \& Luo, H. (2005). Difficult translation points of English terms in biomedicine. Translation of Science and Technology in China, 18(4), 5-7, 10.

Zhang, C. X. (2008). A study of functional purpose theory and application to translation. Changsha: Hu'nan Normal University Press. 
Zhu, H. B., \& Li, X. M. (2017). Proofreading of the abstracts of medical articles from a perspective of functional purpose. Journal of Liaoning College of Economic and Managerial Cadres, (4), 68-70, 109. 